\title{
Energetic costs in the relationship between bitterling and mussels in East Asia
}

\author{
CAROLINE METHLING ${ }^{1}$, KAREL DOUDA ${ }^{2}$, HUANZHANG LIU ${ }^{3}$, ROMAIN ROUCHET $^{1}$, \\ VERONIKA BARTÁKOVÁ ${ }^{1}$, DAN YU ${ }^{3}$, CARL SMITH $^{1,4,5,6}$ and MARTIN REICHARD ${ }^{1, *}$ \\ ${ }^{1}$ The Czech Academy of Sciences, Institute of Vertebrate Biology, Brno, Czech Republic \\ ${ }^{2}$ Department of Zoology and Fisheries, Czech University of Life Sciences Prague, Prague, Czech Republic \\ ${ }^{3}$ The Key Laboratory of Aquatic Biodiversity and Conservation, Institute of Hydrobiology, Chinese \\ Academy of Sciences, Wuhan, China \\ ${ }^{4}$ Department of Ecology and Vertebrate Zoology, University of Łódź, Eódź, Poland \\ ${ }^{5}$ School of Biology, University of St Andrews, St Andrews, UK \\ ${ }^{6}$ Bell Pettigrew Museum of Natural History, University of St Andrews, St Andrews, UK
}

Received 31 July 2018; revised 11 October 2018; accepted for publication 11 October 2018

\begin{abstract}
Bitterling fishes and unionid mussels are involved in a two-sided co-evolutionary association. On the one side, bitterling exploit unionids by ovipositing in their gills. On the other side, unionids develop via a larval stage (glochidium) that attaches to fish gills. Both interactions are parasitic and expected to have negative consequences for the host. Here, we examine the effects of this association on the metabolic rates of mussel and fish hosts by measuring oxygen uptake rates $\left(\mathrm{MO}_{2}\right)$. Measurements were performed on two widespread and broadly coexisting species, namely the rose bitterling Rhodeus ocellatus and Chinese pond mussel Sinanodonta woodiana. As predicted, we observed an increase in routine $\mathrm{MO}_{2}$ in mussels parasitized by bitterling, but only when hosting early stages of bitterling embryos that reside in the interlamellar space of the gills and obstruct water circulation. Hosting later-stage bitterling embryos (that reside in the suprabranchial cavity outside the host gills) was not associated with a higher routine $\mathrm{MO}_{2}$. We did not observe an acute negative effect of glochidial infestations on maximal oxygen uptake rate ( $\left.\mathrm{MO}_{2} \mathrm{max}\right)$, but glochidia-infested bitterling showed consistently lower oxygen consumption rates during recovery from $\mathrm{MO}_{2}$ max. Our results suggest that acute costs of this mutually parasitic relationship might be mitigated, at least in part, by adaptations to limit infestation rates.
\end{abstract}

ADDITIONAL KEYWORDS: Acheilognathinae - branchial parasites - evolutionary arms race - metabolic rate Unionidae.

\section{INTRODUCTION}

Host-parasite interactions are evolutionarily dynamic relationships that often involve costly consequences of parasitism for hosts. Parasites decrease fitness when hosts divert resources into increased maintenance costs, for example by the host mounting an immune response or engaging in tissue repair (Robar et al., 2011), leaving less energy available to direct towards other metabolic functions, such as growth and reproduction.

The relationship between bitterling fishes and unionid mussels (Mills \& Reynolds, 2003; Reichard et al., 2010; Rouchet et al., 2017) is an outstanding example

*Corresponding author. E-mail: reichard@ivb.cz of a two-sided host-parasite association. In this relationship, bitterling parasitize mussels by ovipositing into their gills and, reciprocally, mussels parasitize bitterling (and other fishes) by encystment of their larvae (glochidia) on fish gills and fins (Smith et al., 2004). Bitterling (Acheilognathinae) are small cyprinid fishes distributed widely in East Asia, with a single species complex in the West Palaearctic (Chang et al., 2014). All bitterling exploit unionids as oviposition sites and for subsequent embryo development (Wiepkema, 1961; Reynolds et al., 1997; Smith et al., 2004). During the breeding period, female bitterling place their eggs in the gills of a mussel through the exhalant siphon of the host mussel. Bitterling eggs lodge in the interlamellar spaces and water tubes of the mussel, and the 
developing embryos display a range of specialized adaptations to ensure that they remain in place (Kim \& Park, 1985; Aldridge, 1999). In the later stages of their development, bitterling embryos move from the water tubes of the gills and reside in the suprabranchial cavity (Aldridge, 1999).

Although bitterling have evolved adaptations to maximize the survival of their offspring, host mussels have evolved counter-adaptations to minimize the costs associated with hosting bitterling eggs and embryos (Smith et al., 2000; Mills \& Reynolds, 2003, Mills et al., 2005; Reichard et al., 2006, 2010). The gills of unionid mussels serve two vital functions: feeding and gas exchange. Given that developing bitterling embryos can potentially disrupt the water flow of the gills and damage the ciliated gill epithelium (Stadnichenko \& Stadnichenko, 1980), the effectiveness of both functions may be compromised by the presence of bitterling embryos in the gills (Mills et al., 2005).

Hosting the embryos of European bitterling Rhodeus amarus was shown significantly to impede the growth of the European mussel Unio pictorum (Reichard et al., 2006). Although bitterling embryos may potentially compete directly with the host mussel for oxygen and nutrients (Spence \& Smith, 2013), the underlying mechanisms behind reduced growth in parasitized mussels are yet to be identified. Elevated maintenance costs from tissue repair and immune responses are assumed to have a negative impact on the growth of host organisms (Robar et al., 2011) and are represented by elevated metabolic rates at rest. To mitigate those costs, mussels have evolved mechanisms to reduce the number of bitterling embryos, primarily by expelling them from the gills using a powerful jet of water generated by rapid shell closure (Kitamura, 2005) and by diverting the ovipositor of a spawning female away from the gill chamber (Reichard et al., 2010).

In turn, unionid mussels have parasitic larvae (glochidia) that are obligatory parasites of fish, including bitterling. Female mussels discharge ripe glochidia into the water column, where they attach to the fins and gills of fish and become encysted by host tissue until they metamorphose into juvenile mussels (Arey, 1932; Dudgeon \& Morton, 1984; Douda et al., 2017a). Encystment of glochidia by the host causes tissue swelling and, in the case of attachment to the gills, can result in fusion of gill filaments and lamellae (Meyers et al., 1980; Howerth \& Keller, 2006; Thomas et al., 2014). The resulting reduction in surface area for gas exchange can lead to respiratory stress and fish mortality at extreme glochidial loads (Howerth \& Keller, 2006; Taeubert \& Geist, 2013). At ecologically relevant loads, glochidial infestations can elicit a suite of physiological and behavioural responses. These include increased ventilation rates (Crane et al., 2011;
Thomas et al., 2014), increased haematocrit (Meyers et al., 1980; Filipsson et al., 2017), immune response (Dodd et al., 2006; Rogers-Lowery et al., 2007; Barnhart et al., 2008), impaired osmoregulation (Douda et al., 2017b) and decreased feeding activity (Crane et al., 2011; Österling et al., 2014; Filipsson et al., 2016). Consequently, glochidial infestation may alter energy budgets in the host by increasing maintenance metabolism (Filipsson et al., 2017) and swimming costs (Slavík et al., 2017), resulting in decreased post-infestation growth rates (Ooue et al., 2017).

The negative effects of glochidia on host energetics may not be limited to maintenance metabolism but may also affect maximal oxygen uptake rate $\left(\mathrm{MO}_{2} \max \right)$ as a direct consequence of impaired gill function. Glochidia, like any other gill parasites, may affect maximal metabolic rate, with ecologically relevant consequences. Impaired gill function can have a direct impact on the ability of a host to escape predators, alter the outcome of agonistic encounters or affect prey capture success (Clark et al., 2013; Norin \& Clark, 2016). By reducing the aerobic scope for activity, it may affect how well a fish copes with environmental perturbations, such as elevated temperature or hypoxia (Claireaux \& Lefrançois, 2007). In Atlantic salmon Salmo salar, amoebic gill disease caused a substantial decrease in both $\mathrm{MO}_{2}$ max and swimming speed (Hvas et al., 2017), and a reduction in maximal swimming speed was observed in sea lice-infested rainbow trout Oncorhynchus mykiss (Wagner \& McKinley, 2004) and glochidia-infested brown trout Salmo trutta (Taeubert $\&$ Geist, 2013). The ability to recover from peak exercise levels can also be compromised in parasitized fish (Wagner et al., 2005), as demonstrated by consistently increased ventilation rates during recovery in glochidia-infested brown trout (Thomas et al., 2014). Bitterling have evolved behavioural adaptations to minimize the risk of glochidial infestation (Rouchet et al., 2017) and decrease glochidial load by inhibiting their attachment and shedding them before their successful metamorphosis (Douda et al., 2017a; Modesto et al., 2018), further suggesting that glochidia represent a significant burden for their fish hosts.

In the present study, we examined the proximate metabolic costs associated with hosting bitterling embryos by mussels and hosting glochidia by adult bitterling. We used two common and widespread species in East Asia, the Chinese rose bitterling Rhodeus ocellatus and the Chinese pond mussel Sinanodonta woodiana. Both species coexist across a large region of East Asia, with overlapping reproductive periods (Dudgeon \& Morton, 1983; Zheng \& Wei, 1999; Kitamura, 2006b), and their association has been relatively well characterized (Kitamura, 2005, 2006a; Douda et al., 2017a; Rouchet et al., 2017). We conducted two experiments. 
First, we used field-collected S. woodiana mussels from a site where they coexist with $R$. ocellatus and measured their routine oxygen consumption in relation to the load of bitterling embryos in their gills. We predicted that hosting bitterling embryos would negatively affect energy budgets of mussels via an increase in mussel routine metabolic rate (RMR). We further predicted a correlation between elevated RMR and the number of bitterling embryos hosted by a mussel, and that this correlation would be stronger for early embryos. Second, we infested adult $R$. ocellatus with glochidia of $S$. woodiana and measured $\mathrm{MO}_{2}$ max after exercise and during recovery. We chose to focus on aspects of aerobic performance, anticipating stronger effects, rather than on maintenance metabolism. We predicted a decrease in $\mathrm{MO}_{2}$ max in infested fish compared with non-infested fish, but an increase in $\mathrm{MO}_{2}$ during recovery, as a result of impaired gill function.

\section{MATERIAL AND METHODS}

\section{ANIMALS AND HUSBANDRY}

Rhodeus ocellatus were collected during late April and early May 2014 from two sites, Lake Bao'an $\left(30^{\circ} 17^{\prime} 25.4^{\prime \prime} \mathrm{N}, 114^{\circ} 43^{\prime} 48.9^{\prime \prime} \mathrm{E}\right)$ and Lake Niushan $\left(30^{\circ} 20^{\prime} 25.0^{\prime \prime} \mathrm{N}, 114^{\circ} 31^{\prime} 48.7^{\prime \prime} \mathrm{E}\right)$, using baited fish traps. Fish were transported in cool, aerated water to the Institute of Hydrobiology (IHB), Chinese Academy of Science, Wuhan, where they were housed in two separate glass aquaria $(1.0 \mathrm{~m} \times 0.75 \mathrm{~m} \times 0.5 \mathrm{~m}$; 30 fish per tank) supplied with dechlorinated tap water and a $20 \mathrm{~mm}$ layer of washed sand. Fish were fed daily with frozen bloodworms and commercial flake food. Water temperature was maintained at $24 \pm 1{ }^{\circ} \mathrm{C}$ using aquarium heaters, with $10 \%$ of the water in each aquarium replaced daily to maintain water quality. Light conditions followed a natural $13 \mathrm{~h}$ light-11 h dark photoperiod. Fish and mussels were maintained for $\geq 14$ days in captive conditions before measurements of oxygen consumption.

Sinanodonta woodiana mussels were collected from earthen fishponds near the town of Jianli, Hubei Province, China $\left(29^{\circ} 42^{\prime} 29.4^{\prime \prime} \mathrm{N}, 112^{\circ} 58^{\prime} 37.5^{\prime \prime} \mathrm{E}\right)$ on 17 and 27 April 2014 (at the peak of the bitterling spawning season). Gravid mussels for experimental infestation by glochidia were collected from Lake Niushan. All mussels were transported in cool, aerated water to the IHB, where they were housed in large plastic tubs (Jianli mussels, $N=43,2000 \mathrm{~L}$; Bao'an mussels $N=13,1350 \mathrm{~L}$ ) containing dechlorinated tap water to a depth of $0.3 \mathrm{~m}$ and continuously aerated. Water temperature was maintained at $24^{\circ} \mathrm{C}$ by air conditioning. Approximately $5 \%$ of the water was replaced daily. Mussels were fed phytoplankton regularly.
Husbandry and experimentation adhered to the legal regulations on animal welfare in China and the Czech Republic. Experiments were concluded by dissection of experimental fish and mussels to estimate the level of their parasitism, and all were killed with an overdose of anaesthetic (MS-222) before dissection.

\section{EXPERIMENTAL INFESTATION OF $R$. OCELLATUS}

Gravid S. woodiana females were used to infest $R$. ocellatus with glochidia. Ripe glochidia were collected by flushing the marsupium with water using a syringe. The viability of glochidia was confirmed by observing their snapping action in a sodium chloride solution, and only glochidia from females with $>90 \%$ viability were used for infesting bitterling (Douda et al., 2017a). A suspension of glochidia was prepared containing $4165 \pm 1916($ mean $\pm \mathrm{SD})$ viable glochidia $\mathrm{L}^{-1}$. Bitterling $(1.00 \pm 0.28 \mathrm{~g})$ were placed in the glochidial suspension for $15 \mathrm{~min}$ and then transferred to an aerated $5 \mathrm{~L}$ bath for $2 \mathrm{~h}$ to rinse off non-attached glochidia before beginning the respirometry measurements. Control (non-infested) fish were exposed to the same protocol, except that these fish were placed in a glochidia-free suspension.

\section{RESPIROMETRY}

For both mussels and bitterling, metabolic rates were estimated indirectly by measuring oxygen consumption rates using computerized intermittent flowthrough respirometry (general procedure reviewed by Steffensen, 1989). Respirometry was performed in an isolated, air-conditioned room $\left(22.0 \pm 0.1^{\circ} \mathrm{C}\right)$ with $24 \mathrm{~h}$ dimmed lighting. Respirometers were placed in a $1.0 \mathrm{~m} \times 0.5 \mathrm{~m} \times 0.30 \mathrm{~m}$ holding tank. Twenty per cent of the water in the holding tank was replaced daily with dechlorinated water from an adjacent reservoir tank. Water temperature was maintained at $24.0 \pm 0.1{ }^{\circ} \mathrm{C}$, and a submersible pump was placed in the holding tank to ensure complete mixing of water. The respirometers were fitted with two sets of tubing: one recirculation loop and one for periodically flushing the respirometer with water from the outside holding tank. Each inlet/outlet was fitted with baffles to ensure proper mixing inside the respirometer. Chamber oxygen partial pressure $\left(\mathrm{pO}_{2}\right)$ was measured with an OXY-4 mini (PreSens, Germany) fibre-optic $\mathrm{O}_{2}$ transmitter, placed in the recirculation loop and recorded by the AutoResp4 software (Loligo Systems, Denmark).

For $S$. woodiana $(N=38$, shell size $101-167 \mathrm{~mm})$, the mussels were removed from their holding tank in the morning, gently brushed to remove epibionts, and transferred to the respirometer holding tank. The following morning, mussels were placed individually 
in the submerged respirometers made from waterand air-tight plastic containers ( 450 or $1100 \mathrm{~mL}$ ). Chambers were periodically flushed for $4 \mathrm{~min}$, followed by a closed $2 \mathrm{~min}$ wait period to reach steady state, with a 10 min closed measuring period. Oxygen consumption was measured continuously for $12 \mathrm{~h}$, after which mussels were dissected to quantify the number of bitterling embryos in their gills. The soft tissue of each mussel was dried for $48 \mathrm{~h}$ at $65^{\circ} \mathrm{C}$ and weighed. The $\mathrm{MO}_{2}$ max of mussels was not estimated because there is no protocol to elicit $\mathrm{MO}_{2}$ max in mussels. All bitterling embryos in the mussel gills originated from natural infestations; no experimental infestations were conducted.

Experimentally infested $(N=12$, mean $\pm \mathrm{SD}$ wet mass: $0.99 \pm 0.22 \mathrm{~g})$ and non-infested $(N=12$, mean \pm SD wet mass: $1.02 \pm 0.33 \mathrm{~g}) R$. ocellatus were first subjected to a 3 min chasing protocol, followed by $30 \mathrm{~s}$ air exposure (Clark et al., 2013) to achieve $\mathrm{MO}_{2} \max$, before being placed in the respirometers (90 $\mathrm{mL}$ cylindrical glass chambers, diameter $45 \mathrm{~mm}$ ). To ensure that $\mathrm{pO}_{2}$ never fell below $80 \%$ saturation during the closed phase, a cycle of 3 min flushing, $1 \mathrm{~min}$ wait and $2.5 \mathrm{~min}$ measurement period was used. The $\mathrm{MO}_{2}$ max was determined as the first measurement after placing the fish inside the chamber (immediately before the closed phase). Fish were then left undisturbed in the chambers over the subsequent $2.5 \mathrm{~h}$, while recording $\mathrm{MO}_{2}$ during recovery, after which the chasing protocol was repeated to obtain a second value of $\mathrm{MO}_{2}$ max. Bitterling RMR was not measured because a reliable RMR estimate requires $\geq 24 \mathrm{~h}$ of continuous $\mathrm{MO}_{2}$ measurements, and estimates of bitterling RMR were not needed for our study aims. All respirometry was done on individuals that had fasted for $24 \mathrm{~h}$ (Nie et al., 2017). After respirometry, bitterling were killed with an overdose of anaesthetic (MS-222), and the total number of glochidia attached to fins, gills and body was quantified under a stereomicroscope.

\section{BITTERLING EMBRYO IDENTIFICATION}

Bitterling embryos were removed during mussel dissections, staged according to Nagata \& Miyabe (1978) and Aldridge (1999) and morphologically determined to the genus level. Morphologically, all recovered embryos belonged the genus Rhodeus and apparently of the same species. Given that morphological identification of Rhodeus embryos is not possible (Liu et al., 2004 ), the embryos were stored in $96 \%$ ethanol for identification by genotyping.

A sample of 15 embryos from 15 different host mussels was genotyped for a 797-bp-long fragment of mitochondrial gene for cytochrome $b(C Y T B)$. Genetic analysis followed the protocol of Bohlen et al. (2006).
Haplotypes were compared with existing sequences using a GenBank Blast search. Bitterling species (Acheilognathinae) are well covered in the GenBank database (Chang et al., 2014; Kawamura et al., 2014), including all Rhodeus species in the study area. A total of seven different CYTB haplotypes (12 polymorphic sites) was detected, and all genotyped embryos were confirmed as R. ocellatus, with an estimated 99-100\% similarity to archived sequences. All generated sequences have been uploaded to GenBank (accession numbers MG544112-MG544118).

\section{DATA ANALYSIS}

The oxygen consumption rate $\left(\mathrm{MO}_{2}\right)$ was derived from the decrease in respirometry chamber oxygen partial pressure $\left(\mathrm{pO}_{2}\right)$ during the measuring period using the function: $\mathrm{MO}_{2}=V\left[\mathrm{~d}\left(\mathrm{pO}_{2}\right) / \mathrm{d} t\right] \alpha$, where $V$ is the volume of the chamber and $\alpha$ is the specific oxygen solubility. Measurements of $\mathrm{MO}_{2}$ where the regression coefficient $(r)$ of the slope $\mathrm{d}\left(\mathrm{pO}_{2}\right) / \mathrm{d} t$ was $<0.96$ were excluded from the analysis (Chabot et al., 2016). This included periods when mussels had closed shells and did not ventilate. All $\mathrm{MO}_{2}$ measurements were corrected for microbial respiration recorded in empty chambers before and after each experiment. All statistical analyses were performed using $\mathrm{R}$ v.3.3.3 ( $\mathrm{R}$ Development Core Team, 2017).

The routine metabolic rate (RMR) of mussels was estimated as the lower tenth percentile of $\mathrm{MO}_{2}$ measurements and expressed per gram of soft tissue dry weight $(\mathrm{dm})$. The effect of bitterling embryos on mussel respiration rate was analysed using a linear model (LM) with Gaussian distribution, with mass-specific $\mathrm{MO}_{2}$ as the response variable and the number of bitterling embryos (logarithmically transformed) as covariate. Given that there were biological reasons to assume a stronger effect of early stage bitterling embryos (which reside in the mussel water tubes) than later stage embryos (which reside in the suprabranchial cavity) (Kim \& Park, 1985; Aldridge, 1999), the same analysis was performed on a subset of mussels hosting early stage embryos. An alternative analysis that directly compared infested and non-infested mussels (rather than using the number of bitterling embryos as a continuous covariate) provided concordant results.

The effect of glochidial load on bitterling $\mathrm{MO}_{2} \max$ was analysed using linear mixed models (LMMs) in the lme4 package (Bates et al., 2015), with mass-specific $\mathrm{MO}_{2} \max$ as response variable and the number of glochidia as predictor. A separate analysis was performed with the total number of glochidia attached (sum of glochidia on body and gills) and glochidia attached to the gills only. Individual fish was included as a random term in the model to accommodate two 
separate $\mathrm{MO}_{2}$ max measurements for each fish. Sex and wet mass were initially included as covariates but had non-significant effects and were excluded from final models. The repeatability of $\mathrm{MO}_{2} \max$ measurements was analysed using the intraclass correlation (ICC) function in the psych package (Revelle, 2017). The effect of glochidial infestation on bitterling respiration rate while recovering from exercise was analysed using a generalized least squares (GLS) model in the nlme package, with mass-specific $\mathrm{MO}_{2}$ as the response variable. Treatment (presence or absence of glochidia), time (2.5-131 min after chasing) and their interaction were included as covariates. Time was included as a random intercept in the model to account for a temporal component from repeated measurements of the same individuals.

\section{RESULTS}

\section{MUSSEL RESPIRATION}

There was no significant effect of hosting bitterling embryos on mussel RMR when both early and late stage embryos were included (LM: $t_{36}=1.04, P=0.315$, adjusted $R^{2}=0.001$; Fig. $\left.1 \mathrm{~A}\right)$. However, for the subset of mussels with early stage embryos (residing in the water tubes of the mussels), there was a significant positive relationship between RMR and the number of early embryos in the gills (LM: $t_{11}=7.72, P=0.018$, adjusted $R^{2}=0.36$; Fig. $\left.1 \mathrm{~B}\right)$. Overall, the mean $\pm \mathrm{SD}$ RMR of mussels was $0.25 \pm 0.06 \mathrm{mg} \mathrm{O}_{2}(\mathrm{~g} \mathrm{dm})^{-1} \mathrm{~h}^{-1}$ (mean \pm SD dry mass: $10.12 \pm 4.42 \mathrm{~g}$ ).

\section{BITTERLING RESPIRATION}

The first and second $\mathrm{MO}_{2}$ max measurements were highly repeatable within individuals $\left(\mathrm{ICC}_{1}=0.595\right.$, $F_{18,19}=3.94, P=0.002$ ). There was no significant effect of glochidia on bitterling $\mathrm{MO}_{2}$ max when all attached glochidia were included (LMM: $t_{18.2}=1.08, P=0.239$ ) or when including only glochidia attached to the gills $\left(t_{18.3}=1.67, P=0.113\right)$, despite a lower $\mathrm{MO}_{2} \max$ in fish with the highest infestation rate (Fig. 2). Between the first and second $\mathrm{MO}_{2}$ max measurement, infested fish had significantly lower $\mathrm{MO}_{2}$ compared with noninfested fish (GLS, treatment effect: $\chi^{2}=5.71$, d.f. $=1$, $P=0.017$ ), but with the same temporal decline in oxygen uptake after the chasing protocol (treatment by time interaction: $\chi^{2}=0.66$, d.f. $=1, P=0.418$; Fig. 3 ).

\section{DISCUSSION}

We examined the proximate energetic costs of reciprocal parasitism between bitterling fish and unionid
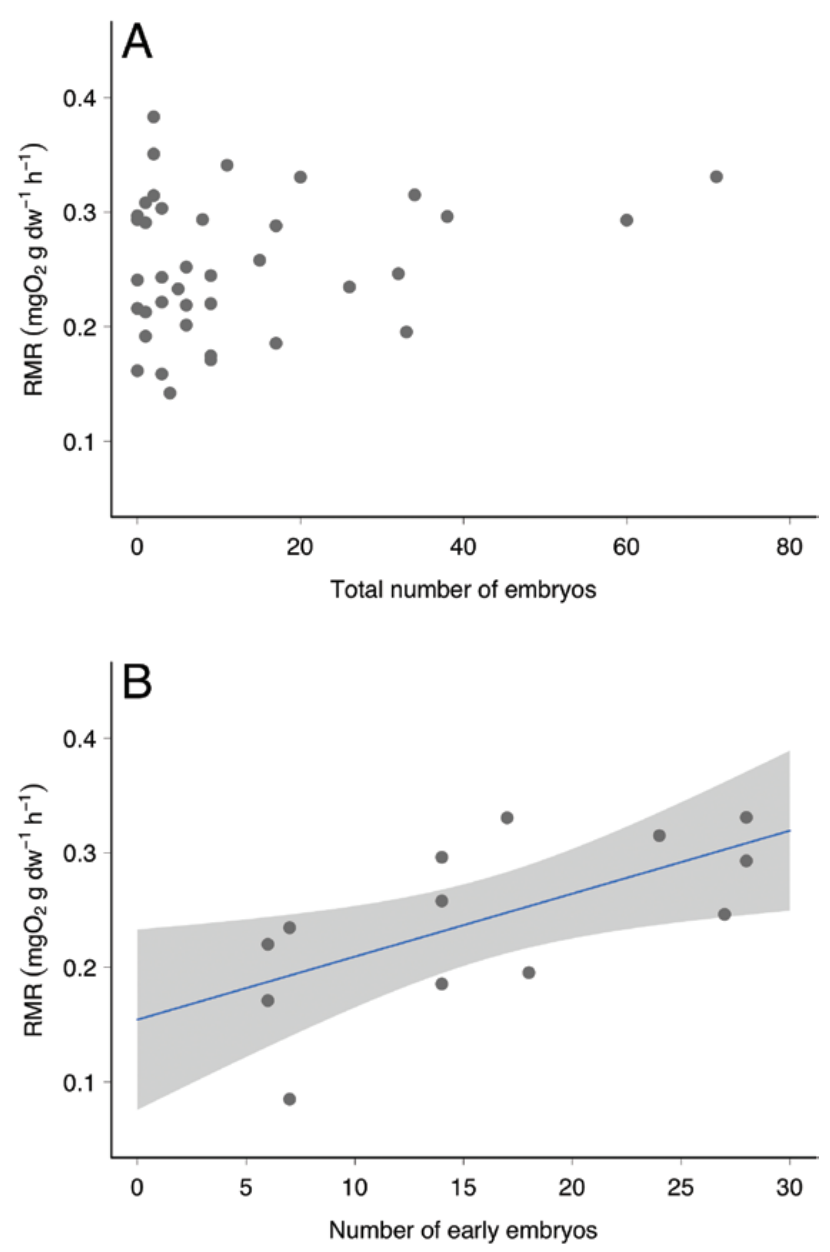

Figure 1. Mass-specific routine metabolic rate (RMR) in Sinanodonta woodiana hosting Rhodeus ocellatus embryos. A, relationship between RMR and the total number of embryos (early and late stages). B, relationship between RMR and the number of early stage embryos. The least squares regression lines are shown, with $95 \%$ confidence intervals indicated by the shaded area.

mussels. We predicted that hosting bitterling embryos would be associated with an elevated routine oxygen uptake rate reflecting increased maintenance costs for infested mussels. We demonstrated that infested mussels had higher routine oxygen uptake rates when hosting bitterling embryos at early developmental stages (which reside between gill lamellae and distract water circulation), but later stages (which occupy the suprabranchial cavity) had no significant impact on mussel respiration. In glochidia-infested bitterling, we predicted a reduced ability to maximize oxygen uptake at maximal metabolic rate and a reduced ability to recover from intense exercise as a direct result of compromised gill function. We found no significant effect of glochidia on $\mathrm{MO}_{2}$ max and, contrary to our predictions, 

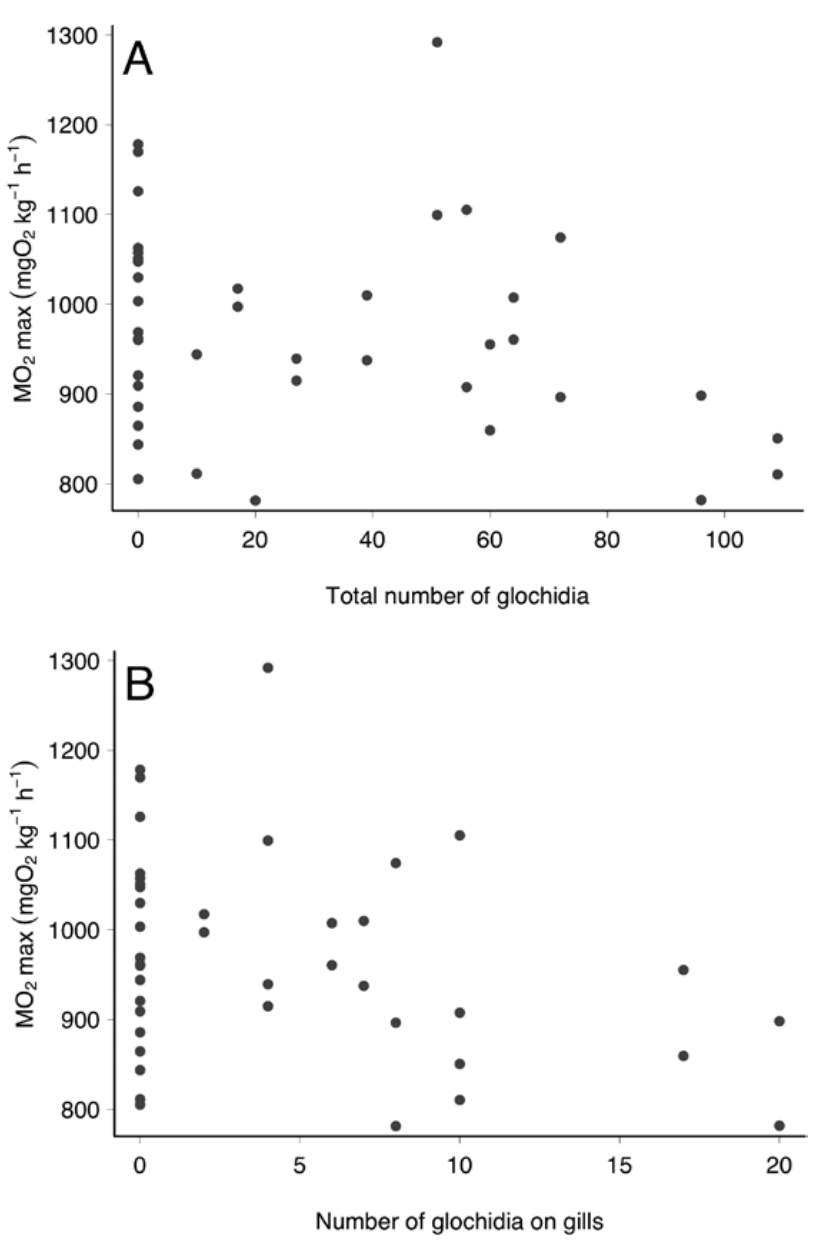

Figure 2. Effect of glochidial load on maximal oxygen consumption rates $\left(\mathrm{MO}_{2} \mathrm{max}\right)$ of Rhodeus ocellatus. A, total number of attached (fins + gills) glochidia. B, glochidia attached to gills only. Repeated measurements are shown.

glochidia-infested bitterling had consistently lower oxygen uptake rates during recovery.

The lack of an increase in routine oxygen consumption rates in mussels hosting late stage bitterling embryos suggests that their presence does not impose a significant energetic cost at this developmental stage. This finding is consistent with the observation that late stage embryos are no longer closely associated with mussel gill epithelia and typically reside in the suprabranchial cavity (Aldridge, 1999). In contrast, harbouring early embryos was associated with increased oxygen uptake rates by mussels. At this stage, bitterling embryos are lodged in the interlamellar space of the gill, obstructing water flow through the gills and distorting the lateral cilia bands on the epithelial surfaces, thereby compromising gill function. This effect has been demonstrated previously in two species of unionids harbouring embryos of European

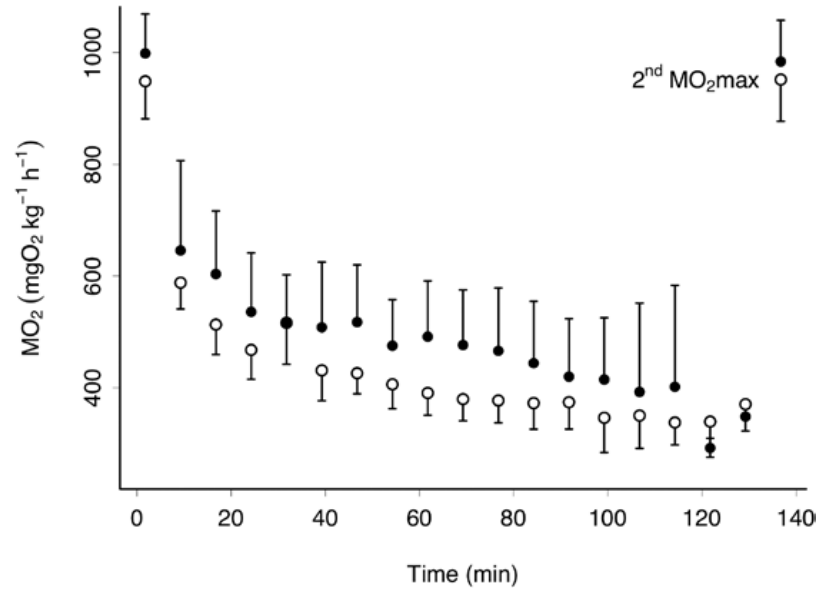

Figure 3. Oxygen consumption rates in glochidiainfested Rhodeus ocellatus. Fish were subjected to a chasing protocol to elicit $\mathrm{MO}_{2} \max$ and left to recover before a second measurement of $\mathrm{MO}_{2}$ max. Points represent mean values of 12 infested (open circles) and ten non-infested (filled circles) individuals. Error bars represents 95\% confidence intervals.

bitterling, with a negative correlation between ventilation rate and the number of bitterling embryos in the gills (Mills et al., 2005). Although we found a positive correlation between the number of embryos and oxygen consumption rate, it does not necessarily imply that mussels had increased ventilation rates. In filter-feeding bivalves, the ventilatory flow is scaled to feeding requirements and greatly exceeds requirements for gas exchange (Krogh, 1941). Oxygen uptake becomes coupled to ventilation only at low flow rates, where the diffusive resistance is increased by a thickening of the diffusive boundary layer on the gill surface (Barker Jørgensen et al., 1986). Furthermore, the ciliary pump is highly energy efficient, and the energetic cost of ventilation in mussels is low (Barker Jørgensen et al., 1986). It is, therefore, possible to achieve increased oxygen uptake concurrent with decreased ventilation, and an elevated $\mathrm{MO}_{2}$ does not necessarily reflect increased energy expenditure from increased ventilation.

It is unlikely that the positive correlation between mussel RMR and the number of embryos is attributable to respiration of the bitterling embryos. There are no known data on the respiration rate of bitterling embryos, but $\mathrm{MO}_{2}$-age relationships were measured at a similar temperature for embryos of a cichlid fish, Pseudocrenilabrus multicolor, with embryos of a comparable size, with estimates of $\mathrm{MO}_{2}=0.05 \mathrm{e}^{0.66 a g e}$ at the age of $0-5$ days and $\mathrm{MO}_{2}=0.62 \mathrm{e}^{0.19 a g e}$ at the age of $>5$ days (Mrowka \& Schierwater, 1988). Early bitterling embryos at 5 days would thus have an estimated 
$\mathrm{MO}_{2}$ of $1.36 \mu \mathrm{g} \mathrm{O}_{2} \mathrm{~h}^{-1}$ and at day $21,33.5 \mu \mathrm{g} \mathrm{O}_{2} \mathrm{~h}^{-1}$, accounting for a maximum of $0.075 \%$ of the measured oxygen consumption. The underlying physiological mechanisms behind an increased routine $\mathrm{MO}_{2}$ in mussels hosting bitterling embryos are unclear but might be associated with immune responses, stress responses or tissue repair (Robar et al., 2011). Regardless of mechanism, an increased maintenance metabolism would limit the amount of energy that can be directed towards growth and might explain the impaired growth observed in mussels hosting European bitterling embryos (Reichard et al., 2006).

Given that our measurements involved naturally infested mussels, active choice of host mussels by bitterling offers an alternative explanation to the positive relationship between the number of early embryos and mussel oxygen uptake rate. Bitterling are capable of perceiving the quality of the mussel as an incubation site for their eggs. The cues used for choice of mussel are the absolute levels of dissolved oxygen in the exhalant siphon and the oxygen gradient between mussel inhalant and exhalant siphons (Smith et al., 2001; Phillips et al., 2017). Therefore, active choice of mussels with high oxygen consumption might explain the positive relationship between mussel oxygen consumption and the number of bitterling embryos. This possibility could be tested by measuring bitterling oviposition preference in mussels with known oxygen consumption levels.

The implications of glochidial infestations for fish respiration are not well understood, but in at least two species of fish, rainbow darters Etheostoma caeruleum and brown trout $S$. trutta, glochidia-infested fish showed increased ventilation frequencies compared with non-infested fish. In rainbow darters, ventilation frequency remained elevated during routine activities throughout the infestation period (Crane et al., 2011), whereas in brown trout glochidiainfested fish had consistently elevated ventilation frequencies after intense exercise, taking longer to return to non-stressed values (Thomas et al., 2014). Glochidia-infested brown trout also showed reduced swimming performance, with reduced critical swimming speeds (Taeubert \& Geist, 2013), all of which points to impaired oxygen uptake capabilities in glochidia-infested fish.

In contrast to these observations and to our results for bitterling presented here, Filipsson et al. (2017) reported a small increase in maximal metabolic rate in juvenile brown trout naturally infested with glochidia of the freshwater pearl mussel Margaritifera margaritifera when compared with non-infested fish. Besides the possibility for species-specific differences in the effects of glochidia on fish hosts, the conflicting outcome might also be explained by temporal effects.
We studied the acute effects of glochidial attachment on $\mathrm{MO}_{2} \max$, whereas Filipsson et al. (2017) observed higher $\mathrm{MO}_{2}$ max in naturally infested fish that may have hosted glochidia for several months, because $M$. margaritifera glochidia remain encysted in their hosts for 10 months (Bauer \& Vogel, 1987). Given that glochidia-infested brown trout also had elevated metabolic rates at rest, they might have made cardiorespiratory compensations to increase $\mathrm{MO}_{2}$ max to sustain aerobic scope for activity in the long term. Notably, immune-challenged mosquitofish Gambusia holbrooki (with elevated maintenance metabolism) were able to upregulate maximal metabolic rate to maintain aerobic scope (Bonneaud et al., 2016). Even when infested with the same parasite, fish may also show speciesspecific responses. Rainbow trout Oncorhynchus mykiss infested with the microsporidium gill parasite Loma salmonae increased both routine and maximal metabolic rate, whereas the brook trout Salvelinus fontinalis lowered routine metabolic rate, with no change in maximal metabolic rate (Powell et al., 2005). Therefore, a response in $\mathrm{MO}_{2}$ max may be both specific to host species and parasite identity and may vary over the course of infestation.

Although we did not observe a significant effect on $\mathrm{MO}_{2} \mathrm{max}$ in glochidia-infested bitterling, the direction of the trend was a reduced $\mathrm{MO}_{2}$ max in the most heavily infested fish, as we predicted. We propose the modest effect to be a consequence of the low number of encysted glochidia on the gills of experimentally infested fish (average: 8.0; range: 0-20) per individual. This number does not reflect unsuccessful experimental infestation, because comparable infestation loads were observed in naturally infested fish from the same population (Douda et al., 2017a). Instead, the low glochidial attachment success on $R$. ocellatus gills may be a consequence of the close co-evolutionary association between bitterling and mussel. All tested bitterling species, including $R$. ocellatus, have lower numbers of glochidia initially attaching to them and substantially lower infestation success than that seen in other freshwater fishes coexisting with S. woodiana (Douda et al., 2017a). Thus, it appears that bitterling can limit the number of glochidia that attach to a level at which the impact of infestation on gill function is negligible.

Contrary to our predictions, glochidia-infested bitterling did not have elevated oxygen uptake rates during recovery compared with non-infested fish but instead had consistently lower $\mathrm{MO}_{2}$. This finding might reflect a behavioural response to infestation in bitterling through a reduction in their spontaneous activity levels (i.e. turning inside the respirometer). Reducing activity levels might even be a general and adaptive response to glochidia infestations. For example, chub Squalius 
cephalus infested with glochidia of Anodonta anatina were less active in open field tests and dispersed less in a natural setting, especially during the early phases of infestation (Horký et al., 2014). In brown trout, glochidial load was negatively correlated with feeding activity (Österling et al., 2014), general activity levels and aggression (Filipsson et al., 2016). Assuming that glochidia attachment acutely impairs $\mathrm{MO}_{2} \max$ and maximal swimming speed (Taeubert \& Geist, 2013), reducing activity levels would be an adaptive response to limit the risk of predation, because the chance of escaping a predator would be reduced. Reduced activity might also be an adaptive response to avoid further infestations given that high glochidial loads may lead to mortality (Howerth \& Keller, 2006; Taeubert \& Geist, 2013). Although we did not record activity levels in bitterling, we propose that the observed decrease in $\mathrm{MO}_{2}$ might have reflected an adaptive behavioural response to glochidial infestation, as observed in other species. This prediction might be tested by measuring activity levels together with oxygen consumption rates pre- and post-infestation.

In conclusion, we demonstrated that unionid mussels infested by early-stage bitterling embryos showed an elevated RMR, although this relationship might have been driven by a selective preference by bitterling for spawning in mussels with high oxygen consumption rates. Rhodeus ocellatus did not suffer a significant acute cost of $S$. woodiana glochidial infestation, measured in terms of a reduced $\mathrm{MO}_{2} \max$. However, glochidia-infested fish had lowered oxygen uptake rates during the recovery phase between $\mathrm{MO}_{2}$ max measurements, possibly owing to a behavioural response. Our results suggest that bitterling and mussels can minimize the acute costs in their bidirectional parasitic relationship. Given the long-term co-evolution between unionid mussels and bitterling in East Asia, mussels are capable of ejecting bitterling embryos to a level that might curtail any negative consequences, whereas bitterling appear capable of limiting their glochidial load to the level that mitigates significant negative consequences.

\section{ACKNOWLEDGEMENTS}

This research was supported by the Czech Science Foundation (13-05872S) and the Strategic Priority Research Program of the Chinese Academy of Sciences (grant no. XDB31040000). C.M., K.D., C.S. and M.R. conceived the study. C.M. performed the experimental work with the help of K.D., H.L., R.R. and D.Y. V.B. genotyped bitterling embryos. C.M. and M.R. analysed data and wrote the paper. We thank four anonymous reviewers for their comments.

\section{REFERENCES}

Aldridge DC. 1999. Development of European bitterling in the gills of freshwater mussels. Journal of Fish Biology 54: 138-151.

Arey LB. 1932. The formation and structure of the glochidial cyst. Biological Bulletin 62: 212-221.

Barker Jørgensen C, Møhlenberg F, Sten-Knudsen $O$. 1986. Nature of relation between ventilation and oxygen consumption in filter feeders. Marine Ecology Progress Series 29: 73-88.

Barnhart MC, Haag WR, Roston WN. 2008. Adaptations to host infection and larval parasitism in Unionoida. Journal of the North American Benthological Society 27: 370-394.

Bates D, Maechler M, Bolker B, Walker S. 2015. Fitting linear mixed-effects models using lme4. Journal of Statistical Software 67: 1-48.

Bauer G, Vogel C. 1987. The parasitic stage of the freshwater pearl mussel (Margaritifera margaritifera L.) I. Host response to glochidiosis. Archiv fuer Hydrobiologie Supplement 76: $393-402$.

Bernays E, Graham M. 1988. On the evolution of host specificity in phytophagous arthropods. Ecology 69: 886-892.

Bohlen J, Slechtová V, Bogutskaya N, Freyhof J. 2006. Across Siberia and over Europe: phylogenetic relationships of the freshwater fish genus Rhodeus in Europe and the phylogenetic position of $R$. sericeus from the River Amur. Molecular Phylogenetics and Evolution 40: 856-865.

Bonneaud C, Wilson RS, Seebacher F. 2016. Immunechallenged fish up-regulate their metabolic scope to support locomotion. PLoS One 11: e0166028.

Brooks DR. 1979. Testing the context and extent of host-parasite coevolution. Systematic Biology 28: 299-307.

Chabot D, Steffensen JF, Farrell AP. 2016. The determination of standard metabolic rate in fishes. Journal of Fish Biology 88: 81-121.

Chang CH, Li F, Shao KT, Lin YS, Morosawa T, Kim S, Koo H, Kim W, Lee JS, He S, Smith C, Reichard M, Miya M, Sado T, Uehara K, Lavoué S, Chen WJ, Mayden RL. 2014. Phylogenetic relationships of Acheilognathidae (Cypriniformes: Cyprinoidea) as revealed from evidence of both nuclear and mitochondrial gene sequence variation: evidence for necessary taxonomic revision in the family and the identification of cryptic species. Molecular Phylogenetics and Evolution 81: 182-194.

Claireaux G, Lefrançois C. 2007. Linking environmental variability and fish performance: integration through the concept of scope for activity. Philosophical Transactions of the Royal Society B: Biological Sciences 362: 2031-2041.

Clark TD, Sandblom E, Jutfelt F. 2013. Aerobic scope measurements of fishes in an era of climate change: respirometry, relevance and recommendations. The Journal of Experimental Biology 216: 2771-2782.

Crane AL, Fritts AK, Mathis A, Lisek JC, Barnhart MC. 2011. Do gill parasites influence the foraging and antipredator behaviour of rainbow darters, Etheostoma caeruleum? Animal Behaviour 82: 817-823. 
Dodd BJ, Barnhart MC, Rogers-Lowery CL, Fobian TB, Dimock RV Jr. 2006. Persistence of host response against glochidia larvae in Micropterus salmoides. Fish \& Shellfish Immunology 21: 473-484.

Douda K, Liu H, Yu D, Rouchet R, Liu F, Tang QY, Methling C, Smith C, Reichard M. 2017a. The role of local adaptation in shaping fish-mussel coevolution. Freshwater Biology 62: 1858-1868.

Douda K, Velíšek J, Kolářová J, Rylková K, Slavík O, Horký P, Langrová I. 2017b. Direct impact of invasive bivalve (Sinanodonta woodiana) parasitism on freshwater fish physiology: evidence and implications. Biological Invasions 19: 989-999.

Dudgeon D, Morton B. 1983. The population dynamics and sexual strategy of Anodonta woodiana (Bivalvia: Unionacea) in Plover Cove Reservoir, Hong Kong. Journal of Zoology 201: 161-183.

Dudgeon D, Morton B. 1984. Site selection and attachment duration of Anodonta woodiana (Bivalvia: Unionacea) glochidia on fish hosts. Journal of Zoology 204: 355-362.

Duyvene de Wit JJ. 1966. Some observations on the European bitterling (Rhodeus amarus). Suid-Afrikaanse Joernaal van Wetenskap 51: 249-251.

Filipsson K, Brijs J, Näslund J, Wengström N, Adamsson M, Závorka L, Österling EM, Höjesjö J. 2017. Encystment of parasitic freshwater pearl mussel (Margaritifera margaritifera) larvae coincides with increased metabolic rate and haematocrit in juvenile brown trout (Salmo trutta). Parasitology Research 116: 1353-1360.

Filipsson K, Petersson T, Höjesjö J, Piccolo JJ, Näslund J, Wengström N, Österling EM. 2016. Heavy loads of parasitic freshwater pearl mussel (Margaritifera margaritifera L.) larvae impair foraging, activity and dominance performance in juvenile brown trout (Salmo trutta L.). Ecology of Freshwater Fish 27: 70-77.

Hall MC, Willis JH. 2006. Divergent selection on flowering time contributes to local adaptation in Mimulus guttatus populations. Evolution 60: 2466-2477.

Heschl A. 1989. Integration of "innate" and "learned" components within the IRME for mussel recognition in the European bitterling Rhodeus amarus (Bloch). Ethology 81: 193-208.

Horký P, Douda K, Matúš M, Závorka L, Slavík O. 2014. Parasite-induced alterations of host behaviour in a riverine fish: the effects of glochidia on host dispersal. Freshwater Biology 59: 1452-1461.

Howerth EW, Keller AE. 2006. Experimentally induced glochidiosis in smallmouth bass (Micropterus dolomieu). Veterinary Pathology 43: 1004-1008.

Hvas M, Karlsbakk E, Mæhle S, Wright DW, Oppedal F. 2017. The gill parasite Paramoeba perurans compromises aerobic scope, swimming capacity and ion balance in Atlantic salmon. Conservation Physiology 5: cox066.

Kawamura K, Ueda T, Arai R, Smith C. 2014. Phylogenetic relationships of bitterling fishes (Teleostei: Cypriniformes: Acheilognathinae), inferred from mitochondrial cytochrome $b$ sequences. Zoological Science 31: 321-329.
Kim YU, Park YS. 1985. Egg development and larvae of the rose bitterling Rhodeus ocellatus. Journal of the Korean Fisheries Society 18: 586-593.

Kitamura J. 2006a. Adaptive spatial utilization of host mussels by the Japanese rosy bitterling Rhodeus ocellatus kurumeus. Journal of Fish Biology 69: 263-271.

Kitamura JI. 2005. Factors affecting seasonal mortality of rosy bitterling (Rhodeus ocellatus kurumeus) embryos on the gills of their host mussel. Population Ecology 47: 41-51.

Kitamura JI. 2006b. Seasonal change in the spatial utilization of host mussels in relation to ovipositor length by female rosy bitterling Rhodeus ocellatus kurumeus. Journal of Fish Biology 68: 594-607.

Krogh A. 1941. The comparative physiology of respiratory mechanisms. Philadelphia: University of Pennsylvania Press.

Liu HZ, Zhu YR, Smith C, Reichard M. 2006. Evidence of host specificity and congruence between phylogenies of bitterlings and freshwater mussels. Zoological Studies 45: 428-434.

Meyers TR, Millemann RE, Fustish CA. 1980. Glochidiosis of salmonid fishes. IV. Humoral and tissue responses of coho and chinook salmon to experimental infection with Margaritifera margaritifera (L.) (Pelecypoda: Margaritanidae). The Journal of Parasitology 66: 274-281.

Mills SC, Reynolds JD. 2002. Mussel ventilation rates as a proximate cue for host selection by bitterling, Rhodeus sericeus. Oecologia 131: 473-478.

Mills SC, Reynolds JD. 2003. The bitterling-mussel interaction as a test case for co-evolution. Journal of Fish Biology 63: 84-104.

Mills SC, Taylor MI, Reynolds JD. 2005. Benefits and costs to mussels from ejecting bitterling embryos: a test of the evolutionary equilibrium hypothesis. Animal Behaviour 70: $31-37$.

Modesto V, Ilarri M, Souza AT, Lopes-Lima M, Douda K, Clavero M, Sousa R. 2018. Fish and mussels: importance of fish for freshwater mussel conservation. Fish and Fisheries 19: 244-259.

Mrowka W, Schierwater B. 1988. Energy expenditure for mouthbrooding in a cichlid fish. Behavioral Ecology and Sociobiology 22: 161-164.

Nagata Y, Miyabe H. 1978. Developmental stages of the bitterling, Rhodeus ocellatus ocellatus (Cyprinidae). Memoirs of Osaka Kyoiku University 3: 171-181.

Nie LJ, Cao ZD, Fu SJ. 2017. Digesting or swimming? Integration of the postprandial metabolism, behavior and locomotion in a frequently foraging fish. Comparative Biochemistry and Physiology. Part A, Molecular \& Integrative Physiology 204: 205-210.

Norin T, Clark TD. 2016. Measurement and relevance of maximum metabolic rate in fishes. Journal of Fish Biology 88: $122-151$.

Ooue K, Terui A, Urabe H, Nakamura F. 2017. A delayed effect of the aquatic parasite Margaritifera laevis on the growth of the salmonid host fish Oncorhynchus masou masou. Limnology 18: 345-351.

Österling EM, Ferm J, Piccolo JJ. 2014. Parasitic freshwater pearl mussel larvae (Margaritifera margaritifera 
L.) reduce the drift-feeding rate of juvenile brown trout (Salmo trutta L.). Environmental Biology of Fishes 97: 543-549.

Phillips A, Reichard M, Smith C. 2017. Sex differences in the responses to oviposition site cues by a fish revealed by tests with an artificial host. Animal Behaviour 126: 187-194.

Powell MD, Speare DJ, Daley J, Lovy J. 2005. Differences in metabolic response to Loma salmonae infection in juvenile rainbow trout Oncorhynchus mykiss and brook trout Salvelinus fontinalis. Diseases of Aquatic Organisms 67: 233-237.

R Development Core Team. 2017. $R$ : a language and environment for statistical computing. Vienna: R Foundation for Statistical Computing. Available at: http://www.r-project.org/

Reichard M, Ondracková M, Przybylski M, Liu HZ, Smith C. 2006. The costs and benefits in an unusual symbiosis: experimental evidence that bitterling fish (Rhodeus sericeus) are parasites of unionid mussels in Europe. Journal of Evolutionary Biology 19: 788-796.

Reichard M, Polačik M, Tarkan AS, Spence R, Gaygusuz O, Ercan E, Ondračková M, Smith C. 2010. The bitterling-mussel coevolutionary relationship in areas of recent and ancient sympatry. Evolution 64: 3047-3056.

Revelle W. 2017. psych: procedures for psychological, psychometric, and personality research. Evanston: Northwestern University.

Reynolds JD, Debuse VJ, Aldridge DC. 1997. Host specialisation in an unusual symbiosis: European bitterlings spawning in freshwater mussels. Oikos 78: 539-545.

Robar N, Murray DL, Burness G. 2011. Effects of parasites on host energy expenditure: the resting metabolic rate stalemate. Canadian Journal of Zoology 89: 1146-1155.

Rogers-Lowery CL, Dimock RV Jr, Kuhn RE. 2007. Antibody response of bluegill sunfish during development of acquired resistance against the larvae of the freshwater mussel Utterbackia imbecillis. Developmental and Comparative Immunology 31: 143-155.

Rouchet R, Smith C, Liu HZ, Methling C, Douda K, Yu D, Tang Q, Reichard M. 2017. Avoidance of host resistance in the oviposition-site preferences of rose bitterling. Evolutionary Ecology 31: 769-783.

Slavík O, Horký P, Douda K, Velíšek J, Kolářová J, Lepič P. 2017. Parasite-induced increases in the energy costs of movement of host freshwater fish. Physiology \& Behavior 171: $127-134$.
Smith C, Reichard M, Jurajda P, Przybylski M. 2004. The reproductive ecology of the European bitterling (Rhodeus sericeus). Journal of Zoology 262: 107-124.

Smith C, Reynolds JD, Sutherland WJ, Jurajda P. 2000. Adaptive host choice and avoidance of superparasitism in the spawning decisions of bitterling (Rhodeus sericeus). Behavioral Ecology and Sociobiology 48: 29-35.

Smith C, Rippon K, Douglas A, Jurajda P. 2001. A proximate cue for oviposition site choice in the bitterling (Rhodeus sericeus). Freshwater Biology 46: 903-911.

Spence R, Smith C. 2013. Rose bitterling (Rhodeus ocellatus) embryos parasitize freshwater mussels by competing for nutrients and oxygen. Acta Zoologica 94: 113-118.

Stadnichenko AP, Stadnichenko YA. 1980. On the effect of bitterling larvae on the lamellibranchid mollusc Unio rostratus gentilis Haas. Gidrobiologicheskii Zhurnal 1980: 57-61.

Steffensen JF. 1989. Some errors in respirometry of aquatic breathers: how to avoid and correct for them. Fish Physiology and Biochemistry 6: 49-59.

Taeubert JE, Geist J. 2013. Critical swimming speed of brown trout (Salmo trutta) infested with freshwater pearl mussel (Margaritifera margaritifera) glochidia and implications for artificial breeding of an endangered mussel species. Parasitology Research 112: 1607-1613.

Thomas GR, Taylor RJ, Garcia de Leaniz C. 2014. Does the parasitic freshwater pearl mussel $M$. margaritifera harm its host? Hydrobiologia 735: 191-201.

Thompson JN. 2005. Coevolution: the geographic mosaic of coevolutionary arms races. Current Biology 15: R992-R994.

Wagner GN, Hinch SG, Kuchel LJ, Lotto A, Jones SRM, Patterson DA, Macdonald JS, Van Der Kraak G, Shrimpton M, English KK, Larsson S, Cooke SJ, Healey MC, Farrell AP. 2005. Metabolic rates and swimming performance of adult Fraser River sockeye salmon (Oncorhynchus nerka) after a controlled infection with Parvicapsula minibicornis. Canadian Journal of Fisheries and Aquatic Sciences 62: 2124-2133.

Wagner GN, Mckinley RS. 2004. Anaemia and salmonid swimming performance: the potential effects of sub-lethal sea lice infection. Journal of Fish Biology 64: 1027-1038.

Wiepkema PR. 1961. An ethological analysis of the reproductive behaviour of the bitterling (Rhodeus amarus Bloch). Archives Neerlandaises de Zoologie 14: 103-199.

Zheng G, Wei Q. 1999. Studies on the reproductive characteristics of female Anodonta woodiana pacifica (Heude) in South Lake, Wuhan. Journal of Huazhong Agricultural University 19: 490-493. 